\title{
The Simon Population Trust
}

Today expressions such as 'population control' and 'eugenics' are seen as implicitly politically incorrect. They evoke suggestions of coercive programmes that seek to solve the problems of society by limiting the number and/or type of people in society. Today such values are usually associated with reactionaries who are trying to retain a conservative society with the traditional values of a colonial past.

Modern opponents of contraception frequently attempt to discredit today's reproductive health care advocacy organisations by drawing attention to their roots in the eugenic and population control movements of the past. Their memory is, of course, correct. The birth control movement in the early part of the last century grew out of concerns about 'racial deterioration' as birth rates among the middle class fell relatively to those of the working class. Sidney Webb, the founder with his wife Beatrice of the Fabian Society, succinctly articulated the view of 'liberal' thinkers - that birth control among the poor should be encouraged. 'In Great Britain, at this moment,' Webb wrote, 'when half, or perhaps two-thirds of all the married people are regulating their families, children are being freely born to the Irish Roman Catholics and the Polish, Russian and German Jews, on the one hand, and the thriftless and irresponsible - largely the casual labourers and other denizens of the one-roomed tenements of our great cities on the other. This can hardly result in anything but national deterioration; or, as an alternative, in this country gradually falling to the Irish and the Jews.' 1

Marie Stopes was of the same mind, referring to her contraceptive cap in terms of racial hygiene.

Traces of concerns about the 'wrong' sort of people having children still taint some of our contemporary family planning discussions. But, for the most part, discussions about the need for effective reproductive health care policies and programmes are motivated by a desire to allow people to fulfil their personal desires to plan their families and to express their sexuality safely.

The history of the Simon Population Trust ${ }^{2}$ is a fascinating account of how a Trust originally ideologically motivated by ideas that developed out of the past, has contributed to a climate where coercive, population-control based notions are no longer tolerated.

The Trust, which Lord Simon established in 1957, had indisputable links to the Eugenics Society. It could not be otherwise with C P Blacker as its Chair. The Trust's objects were shaped by an understanding that would have been familiar to the early Fabians, that social problems could be resolved by limiting population to fit the available resources. They were: 'to promote the relief of poverty and the improvement of standards of health throughout the world, thereby making possible a better life for mankind by (i) promoting a better understanding of the problems of world population and resources, and (ii) encouraging such research, education or other action in any part of the world as may contribute to the adjustment of population to resources.'

But these were ideas of their time, and as times have changed, the Simon Population Trust too began to shift its emphasis towards the need for sexual emancipation and individual choice in fertility regulation.

By the time the Simon Population Trust expended its resources, it had been associated with research and development of a wide range of modern reproductive health care projects. In particular, the Trust's work in relation to sterilisation and abortion techniques has benefited millions of couples around the world.

The Trust stands as an illustration of how all organisations are products of their times, and how they must be assessed by the standards of their day. It should be remembered as a courageous funder of controversial initiatives that have come to raise the quality of life for millions worldwide.

Statements on funding and competing interests

Funding. The author has received research funding from the Simon Population Trust.

Competing interests. See statement on funding.

\section{Ann Furedi}

Director of Communications, Human Fertilisation and Embryology Authority, Paxton House, 30 Artillery Road, London E1 7LS, UK. E-mail: anne-furedi@easynet.co.uk

References
1 Webb S. The decline in the birth rate. Fabian Tract No. 13. London: The Fabian Society, 1907.
2 Kane P. The Simon Population Trust: a brief history. J Fam Plann Reprod Health Care 2002;
28(2): SPT1-SPT12.

Editor's Note. Circulated with this issue of the Journal is a history of the Simon Population Trust, which has recently been wound up after 44 years. Publication of this history has been funded by the Simon Population Trust and it is not a supplement of the Journal. 